\title{
La revolución de puerto en puerto hacia la capital: la vertiente marítima de la "Gloriosa" y la llegada de Prim a Madrid"
}

\author{
Alberto Cañas de Pablos ${ }^{2}$
}

Recibido: 22 de enero de 2017 / Aceptado: 21 de diciembre de 2017

Resumen. Tras el estallido de la Gloriosa Revolución en 1868 en Cádiz, Prim recorrió diferentes puertos mediterráneos españoles comprobando el estado de la revolución o incluso iniciándola en algún caso. La ruta seguida no ha estado siempre bien definida en la historiografía. El presente artículo analiza el carácter y rasgos de los recibimientos y actos públicos de que fue objeto Prim en ese trayecto, y su influencia en ellos. La prensa y la historiografía local serán la base principal para constatar el auténtico recorrido y la ascendiente real del catalán en la adhesión de las ciudades costeras a la Revolución. Palabras clave: Juan Prim, Revolución Gloriosa, carisma, 1868, Isabel II, Cádiz, Cartagena, Barcelona.

\section{[en] The Revolution from port to port: "Gloriosa's" maritime aspect}

\begin{abstract}
After the beginning of "Gloriosa" Revolution in 1868 in Cádiz, Prim went across different Spanish Mediterranean ports, checking the Revolution's development or even starting it in some cases. The followed route has never been well defined by historiography. This article analyses the nature and characteristics of the welcomes and public acts made for Prim on that tour, and his influence on them. Local press and historiography will be the main basis to confirm the real journey and Prim's authentic ascendency over the joining of the coastal cities to the Revolution.
\end{abstract}

Keywords: Juan Prim, Gloriosa revolution, charisma, 1868, Isabel II, Cádiz, Cartagena, Barcelona.

Sumario. Introducción. 1. Cambio de rumbo: la (auténtica) ruta del viaje mediterráneo de Prim. 2. Andalucía, Ceuta, Murcia y Valencia. 3. Cataluña: éxtasis público en Barcelona y el retorno a casa en Reus. 4. Madrid: última parada. 5. Conclusiones. 6. Referencias bibliográficas. 6.1. Estudios. 6.2. Prensa.

Cómo citar: Cañas de Pablos, A. (2017): "La revolución de puerto en puerto hacia la capital: la vertiente marítima de la "Gloriosa" y la llegada de Prim a Madrid ". Cuadernos de Historia Contemporánea 40, 199-218.

1 Programa de Financiación de la Universidad Complutense de Madrid-Santander Universidades, Convocatoria 2014 (CT4-14). Una primera versión del texto apareció como “¿Portando la tea? El viaje mediterráneo de Prim en septiembre y octubre de 1868” en González Madrid, Damián; A., Ortiz Heras, Manuel y Pérez Garzón, Juan Sisinio (eds.): La Historia, lost in translation? Actas del XIII Congreso de la Asociación de Historia Contemporánea. Cuenca, Ediciones de la Universidad de Castilla-La Mancha, 2017, pp. 975-986.

2 Universidad Complutense de Madrid. email: acpablos@ucm.es 


\section{Introducción}

"La Gloriosa Revolución", ocurrida entre septiembre y octubre de 1868, fue uno de los acontecimientos más importantes de la segunda mitad del siglo XIX en España. Asimismo, supuso el momento de mayor dominio político de los liberales progresistas, encabezados en ese momento por el reusense Juan Prim, en toda la centuria. Desde su inicio en Cádiz, los líderes revolucionarios avanzaron geográficamente de dos formas distintas. La primera de ellas se desarrolló por tierra y estuvo liderada por Serrano. Esta ruta culminó con su triunfo en la batalla de Alcolea (Córdoba) sobre las tropas gubernamentales dirigidas por Novaliches. La segunda fue una travesía por mar, comandada en ese caso por Juan Prim, quien navegó hacia el norte surcando los puertos más importantes de la costa mediterránea peninsular española hasta llegar a Barcelona.

En aquel viaje, el militar catalán fue testigo de la importancia que su persona tenía en la expresión pública de las actitudes políticas. Se sucedieron incontables homenajes, recepciones y desfiles multitudinarios en su honor durante aquellos días. Aunque no siempre fue él el desencadenante de la adhesión a la revolución de las ciudades por las que pasaba (en ocasiones llegaba cuando ese hecho ya se había producido), siempre sirvió, como mínimo, de referencia que consolidaba el apoyo al movimiento. Ostentaba sin duda el mayor ascendiente entre los militares que habían participado en el pronunciamiento en la bahía de Cádiz. Una de las consecuencias negativas de ello fue atribuirle, por parte de la historiografía, un papel demasiado crucial, difundiendo la imagen de un Prim que iba "prendiendo la tea revolucionaria" allá por donde iba, cuando las fuentes muestran que lo más habitual fue que llegase a ciudades ya unidas a los rebeldes.

La denominada "Gloriosa Revolución" dio comienzo en el mar. En concreto, en la entrada al puerto de Cádiz. Fue allí donde el 17 de septiembre de 1868 una escuadra constituida por las fragatas Villa de Madrid, Zaragoza, y Tetuán, los vapores Isabel II, Vulcano y Ferrol y las goletas Edetana y Ligera fue colocándose en línea, en orden de combate. ${ }^{3}$ Ese fue el primer acto y desencadenante de unos sucesos que terminaron con la salida de la reina Isabel II del país para siempre. El alzamiento fue ganando adeptos por toda España, siendo Andalucía uno de los primeros territorios en sumarse al mismo. La batalla del puente de Alcolea, cerca de Córdoba (28 de septiembre), constituyó el punto de inflexión que allanó el camino para el avance de la revolución más allá de Sierra Morena y consolidó su triunfo final. A bordo de la fragata Zaragoza el conde de Reus fue visitando durante las tres semanas siguientes los puertos españoles del Mediterráneo. En algunas ciudades fue el revulsivo para que se unieran a la revolución, mientras que en otras su llegada fue un motivo de júbilo para las Juntas Revolucionarias ya formadas. Reus y Madrid, ya en el interior, fueron las dos últimas paradas de importancia en esta travesía. Sin embargo, por motivos de espacio y de relevancia global para la cuestión tratada, no se incluyen en el presente artículo las paradas que efectuó el tren en el que viajó Prim desde Lérida hasta la capital de España. La Revolución ya había triunfado, por lo que la influencia real de la presencia de Prim en ese momento había quedado limitada, y, por otro lado, excepto Zaragoza, las paradas se produjeron en localidades más pequeñas. Además,

Bernal, Antonio Miguel: “Andalucía caciquil y revolucionaria (1868-1936)”, en VV.AA. Historia de Andalucía. Volumen VIII: La Andalucía contemporánea, Barcelona, Cilsa, 1981, p. 13. 
Prim tenía "prisa" por llegar cuanto antes a Madrid y encabezar junto a Serrano la siguiente fase de la Gloriosa.

Este artículo está centrado en las características que tuvieron los recibimientos y actos públicos centrados en la figura de Prim durante el viaje victorioso de los revolucionarios, algunos de ellos celebrados cuando él no estaba presente (por ejemplo, la exhibición de retratos o la colocación de colgaduras en los edificios). Las historias de la "Gloriosa" y las biografías de Prim no han sido ajenas a su periplo marino, pero ese viaje no se ha estudiado como fenómeno en sí mismo; de ahí el interés y la novedad que pueda representar este artículo en la historiografía relativa a la "Gloriosa".

Con el triunfo de la Gloriosa reapareció la iconografía liberal-progresista que ya había sido mostrada en momentos anteriores del siglo. Durante los primeros días de efervescencia revolucionaria se exhibió un retrato de Prim sobre un carro engalanado por las calles de Madrid. Imágenes tanto suyas como de Espartero (el eterno grand old man del progresismo español) ${ }^{4}$ desfilaron en Valladolid, Barcelona y Mataró, ${ }^{5}$ entre otras ciudades. No había descendido ni un ápice la popularidad ganada por los espadones, dada su capacidad para condensar y representar los valores progresistas y revolucionarios. Parecía una necesidad la referencia a un líder progresista militar, pues el mito Prim venía a sustituir al mito Espartero. ${ }^{6}$ Como recoge Comellas, ${ }^{7}$ Espartero inauguró la larga serie de militares políticos con su pronunciamiento de 1840. Desde entonces, y hasta la muerte de Prim en 1870, la mayoría de los ministerios fueron presididos por militares, como militares eran los jefes de los partidos políticos (Narváez del moderado, O'Donnell del unionista, el duque de la Victoria y luego Prim del progresista). Igual sucedió con las dos regencias (Espartero, 18401843, Serrano, 1869-1870) previas a la Restauración.

Se han empleado tres clases de fuentes en la elaboración de este artículo, empezando por la historiografía dedicada a la figura del general, con especial atención en aquellas obras elaboradas por autores catalanes, que tradicionalmente han sido en mayor medida (pero no en exclusiva) quienes se han dedicado a la vida y trayectoria de Prim. Por otro lado, se tienen presentes también las obras pertenecientes al campo de la historia local del Sexenio centradas en las ciudades que forman parte del trayecto de la escuadra. Finalmente, se recurre a la prensa escrita a nivel nacional, pero también los diarios locales, que permiten una aproximación más directa a los hechos en algunas ciudades.

\section{Cambio de rumbo: la (auténtica) ruta del viaje mediterráneo de Prim}

Durante los últimos 150 años, se ha reincidido en un error sobre la secuencia de arribadas sucesivas que realizó el general Prim. Diversos autores han reproducido la siguiente secuencia de ciudades como la que realizó Prim en el otoño de 1868:

4 Esdaile, Charles J.: "Prohombres, aventureros y oportunistas: la influencia del trayecto personal en los orígenes del liberalismo en España”, en Alda Blanco y Guy Thompson (eds.): Visiones del liberalismo: politica, identidad y cultura en la España del siglo XIX. Valencia: Universidad de Valencia, 2008, p. 77

5 Zurita Aldeguer, Rafael: "El Progresismo. Héroes e historia de la nación liberal”, en María Cruz Romeo y María Sierra (coords.): La España Liberal. 1833-1874, Zaragoza, Marcial Pons-Prensas Universitarias de Zaragoza, 2014, p. 335. Para el caso de Mataró, ver Crónica Mataronesa, nº 40, 4 de octubre de 1868, p. 3.

6 Bahamonde, Ángel y Martínez, Jesús A.: Historia de España. Siglo XIX, Madrid, Cátedra, 2011, p. 533.

7 Comellas, José Luis: La España de la generación romántica, Barcelona, Folio, 2009, pp. 13-14. 
Málaga (23 de septiembre), Almería (25), Cartagena (26), Murcia (30, ida y vuelta en tren desde la anterior), Valencia (2 de octubre) y Barcelona (3) fueron las ciudades que visitó en su periplo, para luego pasar por Tarragona y Reus (4) camino ya de Madrid, donde llegó el día 7 de octubre. Sin embargo, la realidad no fue esa, y el recorrido descrito en diversas obras ${ }^{8}$ se ha demostrado como equivocado. Algunos autores añadían Ceuta y Alicante a la ruta, ${ }^{9}$ pero, aunque la presencia de Prim en la primera ha quedado demostrada, ${ }^{10}$ (se desarrolla brevemente este punto en un apartado posterior), no ocurre lo mismo en el segundo caso. Existe algún error más, como por ejemplo la fecha de la llegada de Prim a Málaga, pues tras un profundo estudio de la bibliografía y de la prensa, se fija el día de la proclama de Prim en la rada de Málaga el 25 de septiembre, el mismo día que llegó. ${ }^{11}$

Otra inexactitud se ha producido con Almería, dadas las múltiples versiones que se han difundido sobre su adhesión al alzamiento de 1868. Hasta ahora la bibliografía había defendido que la simple colocación de los barcos en la entrada del puerto almeriense (con Prim en uno de ellos), sin que mediara desembarco alguno, había sido suficiente para que la ciudad se uniera. En palabras literales de las mismas fuentes que daban un recorrido equivocado para Prim, el alzamiento triunfó entre los almerienses "a la vista de la escuadrilla". No fue eso lo que ocurrió: Prim pasó de largo de la ciudad, dirigiéndose directamente a Cartagena desde Málaga. En realidad, Almería se pronunció el día 28, cuando el conde de Reus ya había llegado a Cartagena. Los acontecimientos fueron los siguientes: el 27 el vapor de guerra Vigilante, con el brigadier Carlos Palanca Gutiérrez al mando, fondeó en el puerto y amenazó con bombardear la ciudad. Esto hizo que el gobernador militar de la misma (Manuel Moreta) se rindiera al día siguiente, formándose en ese momento la Junta Revolucionaria. El disparo de un cañonazo y los vivas a la libertad y a la soberanía nacional anunciaron a la población "que era llegada la hora de que Almería secundara el glorioso alzamiento de Cádiz". ${ }^{12}$ Hubo un recibimiento popular masivo en el puerto, donde los marinos fueron aclamados. El brigadier Palanca desembarcó y se dirigió al Ayuntamiento, donde fue homenajeado hasta que el día 2 de octubre tuvo que marcharse de la ciudad, al ser reclamado precisamente por Prim. ${ }^{13}$ Pueden establecerse comparaciones directas entre la experiencia de Palanca en Almería y las que vivió Prim en otras ciudades, si bien las resistencias mostradas inicialmente indican el menor grado de influencia de Palanca en comparación con su superior. Junto a algunas localidades del Estrecho de Gibraltar y el caso especial de Murcia

8 Orellana, Francisco José: Historia del General Prim, Barcelona, Empresa Editorial La Ilustración, Tomo II, 1872, p. 912. Santovenia, Emeterio: Prim, el caudillo estadista, Madrid, Espasa-Calpe, 1933, p. 187. Poch Noguer, José: El General Prim, Madrid, Sarpe, 1986, p. 108. De la Fuente Monge, Gregorio: Los revolucionarios de 1868. Élites y poder en la España liberal, Madrid, Marcial Pons, 2000, p. 59.

9 Biografía del General Don Juan Prim, Conde de Reus y Marqués de Castillejos, Madrid, Despacho Calle Juanelo 19, 1876, p. 21.

10 Gómez Barceló, José Luis: "El siglo XIX”, en VV.AA. Historia de Ceuta. De los orígenes al año 2000. Volumen 2: De los Austrias al siglo XXI, Ceuta, Instituto de Estudios Ceutíes, 2009, p. 161.

11 La Correspondencia de España, no 3969,30 de septiembre de 1868, p. 3

12 Caro Cancela, Diego: Andalucía y la Revolución del 68, Granada, Caja Granada, 2008, pp. 37-38. Sanz Cruz, Mario: Faro de Mesa Roldán. (Apuntes para una historia), Almería, Instituto de Estudios Almerienses, 2003, p. 30. La proclama en Martínez López, Fernando: "Del sufragio universal a la solidaridad. Salmerón en la política republicana almeriense (1869-1908)", en Amate Martínez, María Cruz (coord.): Nicolás Salmerón y Alonso (1837-1908). Semblanzas, Almería, Instituto de Estudios Almerienses, 2008, p. 138.

13 Martínez López, Fernando: Los republicanos en la política almeriense del siglo XIX, Málaga, Unicaja, 2006, pp. 60-61. 
capital, la lista completa de llegadas durante aquellas dos semanas es la siguiente: Jerez de la Frontera y regreso a Cádiz en tren (21 de septiembre), Tarifa y Algeciras (23), Ceuta (24), Málaga (25), Cartagena (26), Murcia (30, ida y vuelta en ferrocarril desde la anterior), Valencia (2 de octubre), Barcelona (3), Tarragona y Reus (4), y Madrid (7 de octubre). Acompañado por el capitán de la Zaragoza José Malcampo y por el general Serrano Bedoya, Prim fue el destinatario de sendos recibimientos y actos festivos, algo que ya había vivido en Alicante, en Madrid y en Cataluña cuando regresó de la denominada "guerra de África" a comienzos de 1860.

Existió cierta confusión sobre el porvenir de los acontecimientos revolucionarios en los primeros días. Después de la batalla de Alcolea se suponía que los dos líderes militares llegarían inmediata y simultáneamente a Madrid ${ }^{14}$ con la intención de hacerse con el poder provisional cuanto antes y controlar la situación. De hecho, se enviaron comisionados que salieron desde Alcázar de San Juan (Ciudad Real) hacia Cartagena y Córdoba en trenes especialmente adornados para la ocasión, que sin embargo no sirvieron para su cometido y volvieron de vacío. Aun así, en Madrid había muchos rumores sobre una inminente entrada de los dos en la capital. Un ejemplo lo encontramos en la información sobre la salida de Prim hacia la capital desde Cartagena en un tren directo, aparecida en La Correspondencia de España,$^{15}$ cosa que no sucedió. Para comprender la dinámica de este viaje es necesario tener en cuenta la mitificación que había logrado la figura de Prim durante los años inmediatamente anteriores a la revolución septembrina, en los que se lo veía como el hombre capaz de solucionar la penosa situación que atravesaba el país. Había logrado convertirse en un "líder político", según la definición de Pitkin, que es pasivo, porque "suple a otros simbólicamente", pero al mismo tiempo es un "artífice de símbolos, que se convierte a sí mismo en un líder aceptado a través de su actividad." Apelaba a las cuestiones emocionales que conforman un carisma desde el punto de vista weberiano del término:

La legitimidad del mando carismático se basa en la fe [de los gobernados] en poderes mágicos, revelaciones y el culto al héroe. Fuente de esta fe es la "demostración" de la cualidad carismática mediante milagros, victorias y otras hazañas, esto es, por medio del bienestar de los gobernados. ${ }^{16}$

\section{Andalucía, Ceuta, Murcia y Valencia}

Como ya se ha explicado, la "Gloriosa" comenzó en Cádiz. Tras la salva de veintiún cañonazos con los que la escuadra indicaba su rebeldía hacia el Gobierno, en las primeras horas del 19, Sánchez Mira, Bolaños, Antich y Guerra hicieron que el regimiento de Cantabria se sublevase. No tardaron mucho en desembarcar Prim, Sagasta y Topete y la multitud los vitoreó, sobre todo al conde de Reus, junto a algún "muera" a los Borbones. El general reusense salió al balcón de la Aduana para recibir el apoyo de la población y dar un breve discurso.

14 La Correspondencia de España, n ${ }^{\text {os }} 3968$ y 3969, 29 y 30 de septiembre de 1868, pp. 1 y 3, respectivamente.

15 La Correspondencia de España, no 3969,30 de septiembre de 1868, p. 2.

16 Pitkin, Hanna Fenichel: El concepto de representación, Madrid, Centro de Estudios Políticos y Constitucionales, 1985, p. 117. Weber, Max: Economía y Sociedad, Ciudad de México, Fondo de Cultura Económica, 1977, p. 193. 
El día 21 Prim inicio su ronda de visitas con su llegada a Jerez de la Frontera, sin salir de la provincia de Cádiz. Previamente se habían dado rumores sobre su llegada, y en cuanto se confirmó la noticia "una multitud inmensa"17 acudió a la calle del Consistorio para saludar al ilustre vencedor de los Castillejos. Se colgó un retrato suyo en el edificio y el general se asomó al balcón para dirigir unas palabras al pueblo, como ya había hecho en Cádiz. Las aclamaciones y vítores cortaban continuamente el discurso. En él manifestó que "el pueblo de Jerez había merecido bien de la patria por los esfuerzos que había hecho en pro del alzamiento nacional". ${ }^{18}$ Más tarde acudió a casa de Pedro López Ruiz (posterior alcalde de Jerez), donde permaneció hasta las 6 de la tarde, mientras una multitud lo vitoreaba desde la calle. Allí pronunció el enésimo discurso del día, con palabras que expresaban "su amor y su entusiasmo" hacia los habitantes de la ciudad. De ahí salió hacia el tren para regresar a la capital provincial. Al otro lado del Estrecho la actitud de las autoridades hacia el alzamiento no estaba clara. La escuadra de Prim primero partió el 23 a Tarifa y Algeciras, donde la guarnición, al ver los buques, hizo gestos de adhesión al alzamiento. El desembarco estuvo rodeado de grandes muestras de reconocimiento al general: "allí tuvimos que arrancar al general de los brazos del pueblo que materialmente lo ahogaba. (...) Por poco nos tiran al agua del delirio que los embargaba". ${ }^{19}$

Embarcó junto al juez de Paz Rafael Orozco y partió hacia Ceuta el 24 de septiembre para que el general Rey se uniese al alzamiento. Además, el coronel Nebot y el Regimiento Fijo a su mando debían trasladarse a la Península del bando revolucionario. El mismo 24 se lograron los dos objetivos. El mencionado Regimiento cruzó el Estrecho y participó activamente en la batalla del puente de Alcolea unos días después. ${ }^{20}$ Fue una discreta misión de precisión político-militar. En aquella ocasión no hubo recibimientos ni algarabías, aunque la adhesión de las tropas ceutíes fue inmediata a la vista de Prim. Málaga fue otro de los grandes escenarios del viaje. Allí llegaron enseguida las noticias de los sucesos de Cádiz, y la revolución se consolidó en la ciudad entre los días 21 y 22. La mañana del lunes 21 la población pidió por las calles que los regimientos de la ciudad (Aragón, de la Princesa y Cuenca) se uniesen a la Revolución en ciernes. Al día siguiente se designó una Junta Popular provisional. ${ }^{21}$ Así pues, en el caso malagueño la presencia de Prim no fue decisiva en la revolución; ya antes de su llegada la ciudad se había unido al levantamiento.

En la historiografía han permanecido discrepancias sobre la fecha concreta de la llegada de la escuadra naval insurrecta. Aun así, las fuentes de mayor consistencia consideran que Serrano Bedoya acompañó a Prim en su entrada en la ciudad el 25. En cuanto al resto del séquito del general, unas añaden a la comitiva a Primo de Rivera, ${ }^{22}$ mientras que otras a quien incluyen es a Milans del Bosch. ${ }^{23}$ En cualquier

17 El Guadalete, $\mathrm{n}^{\circ}$ 4892, 22 de septiembre de 1868, p. 2.

18 Anguera, Pere: Prim. Biografia de un conspirador, Barcelona, Edhasa, 2003, p. 527.

19 De Lara, D. M. M.: Cronista de la Revolución Española de 1868, Barcelona, Imp. de Celestino Verdaguer, 1868, p. 54.

20 Gómez Barceló, José Luis: "El siglo XIX...”, p. 161.

21 Morales Muñoz, Manuel: "La Gloriosa en Málaga: del clamor revolucionario al fracaso de las expectativas populares”, Baetica, 16, 1994, p. 196. Ver también El Avisador Malagueño, suplemento, 22 de septiembre de 1868.

22 Vidal Delgado, Rafael: Gloria y muerte en Málaga. Tomo I. Una revolución en busca de un Rey, Málaga, Caligrama Ediciones, 2007, p. 39.

23 Bretón García, Alicia: La Gloriosa en Málaga. Estudio Económico y Político sobre la Revolución de 1868 en Málaga, Málaga, Diputación Provincial de Málaga, 1986, p. 124. 
caso, el muelle estaba repleto de curiosos, y allí esperaba la Junta Provisional de Gobierno y una compañía del Regimiento de la Princesa, con bandera y música, ${ }^{24}$ a los miembros de la escuadra. El Avisador Malagueño dio cuenta del recibimiento en la ciudad:

Pocas veces hemos visto un entusiasmo tan unánime como el que despertó en la muchedumbre la presencia de los populares generales, que desembarcaron en medio de los no interrumpidos vivas de los que acudían a saludarles, y cuya avidez por conocerles apenas podía contener la fuerza popular abierta en dos filas hasta la Alameda. ${ }^{25}$

Prim se alojó en la Fonda de la Alameda de la ciudad, donde se hizo en su honor un almuerzo con más de cien invitados y desde cuyo balcón arengó a las tropas, "aunque el bullicio de éstos [los soldados] hizo que se le oyera poco". ${ }^{26}$ Su recorrido en carroza descubierta por las adornadas calles malagueñas fue un éxito. Seguidamente presidió una sesión de la Junta Revolucionaria donde presentó a Serrano Bedoya como nuevo Capitán General de Andalucía y al brigadier Marín como flamante gobernador militar de la plaza y de la provincia. ${ }^{27}$ Desde Málaga hizo llegar una proclama pública a la ciudad de Granada, única capital andaluza donde la insurrección no había triunfado todavía. Dicho texto y la presión popular hicieron que la guarnición de la ciudad se uniese a la causa revolucionaria, ${ }^{28}$ por lo que en ese caso puede decirse que el impulso del general sí fue decisivo. Ese mismo día salió de la ciudad, pero aún anclado en la rada del puerto y justo antes de partir redactó una proclama para los malagueños. ${ }^{29}$ En ella, Prim defendió que "el pueblo de Torrijos" (los malagueños) había sabido corresponder al "pueblo de Riego" (Cádiz) y que habían conseguido "recuperar la libertad" que merecían. Las referencias a ambos mártires liberales servían para establecer una continuidad "dinástica" entre héroes del pasado y sus "sucesores", los líderes políticos del momento.

Cartagena, donde llegó el día 26, fue la parada más larga de todo el viaje. La reacción de la ciudad era observada con notable atención tanto por gubernamentales como por revolucionarios, dado que allí se encontraba el mayor arsenal de fusiles en manos del gobierno, además de ser el puerto de referencia para la Marina y su Escuadra del Mediterráneo. No había duda sobre sus capacidades para resistir a la sublevación; la decisión que tomase la ciudad sería un punto de inflexión en el devenir posterior de los acontecimientos. La adhesión de Cartagena a la "Gloriosa" hubo que ganársela: el proceso allí fue el más largo y complejo de toda la ruta. Las tres fragatas rebeldes Zaragoza, Villa de Madrid y Princesa de Asturias (esta última se acababa de poner en rebeldía pues había salido poco antes del propio puerto de Cartagena) se colocaron a la entrada marítima de la ciudad, desde donde podían ser vistos por la población cartagenera. La actitud no era receptiva en un primer momen-

24 Díaz De Escovar, Narciso: Anales de Málaga: algunos datos sobre la revolución de septiembre (18 de septiembre de 1868 a 22 de enero de 1869), Málaga, s.n., ca. 1869, p. 16.

25 El Avisador Malagueño, 26 de septiembre de 1868, p. 1. Citado en Vidal Delgado, Rafael: Gloria y muerte..., p. 40.

26 Díaz De Escovar, Narciso: Anales de Málaga..., p. 16.

27 Vidal Delgado, Rafael: Gloria y muerte..., p. 40.

28 Anguera, Pere: Prim. Biografia de..., p. 528.

29 La Correspondencia de España, no 3969,30 de septiembre de 1868, p. 3. 
to, pues la Zaragoza envió un bote para establecer contacto, que fue rechazado por las autoridades.

Sin embargo, la situación del gobernador militar era bastante compleja, ya que la inquietante visión de los buques en la entrada del pueblo contribuyó a encender gradualmente los ánimos de los habitantes de la ciudad, que el día 27 por la tarde ya se hallaba en plena sublevación popular ${ }^{30}$ y la situación se tornó insostenible. Las autoridades huyeron hacia Murcia primero y más hacia el interior peninsular después. Finalmente la guarnición de la plaza, las fuerzas de la Marina y el pueblo de Cartagena ${ }^{31}$ se unieron al alzamiento. Con la adhesión cartagenera a los sublevados, sólo un triunfo decisivo del marqués de Novaliches ante Serrano en Alcolea habría contenido la revolución. Su fracaso condenó al sistema vigente. E1 29 de septiembre las tropas desfilaron por la calle del Aire, frente a la casa de Vera, donde se hallaba alojado Prim, en medio de sonoras ovaciones. Participaron distintos cuerpos: el regimiento de Burgos, la Guardia Civil, la rural y por último el segundo regimiento de artillería. ${ }^{32}$ Al día siguiente se constituyó la Junta de Gobierno provisional de la ciudad, ${ }^{33}$ como ocurría en todos los lugares que se unían a los revolucionarios.

Merece una mención especial el caso de Murcia capital, a pesar de estar alejada de la costa. Allí Prim "impulsó" la adhesión a la revolución sin que hiciera falta que estuviera presente en inicio. La simple mención de su nombre y la cercanía de su persona eran suficientes. La situación se desarrolló de la siguiente manera: el 29 se había constituido la Junta Revolucionaria de la ciudad, cuyos miembros enviaron un telegrama al general para que tuviera constancia de ello. La importancia de la figura del conde de Reus en los acontecimientos había quedado plasmada ese mismo día en la alocución que la Junta Revolucionaria de Murcia hizo incluir en el suplemento de La Paz de Murcia. Sirva como ejemplo el siguiente fragmento de la misma:

Ante los muros de la moderna Cartago ha llegado el héroe de los Castillejos y nuestros vecinos y hermanos ven tremolar sobre sus castillos, hoy ya convertidos en inexpugnables baluartes de la causa nacional, la bandera de la libertad, gloriosa enseña por la que todos debemos compartir. ${ }^{34}$

Como puede verse en estas líneas, se apeló de forma directa a la llegada del héroe Prim en persona a Cartagena como un acicate complementario para que la llamada a los murcianos a unirse a las acciones de la Junta y "confiar" en ella fuese efectiva. Y lo fue. Tras el éxito, allí acudió el general en ferrocarril expreso el día 30 y "fue recibido con el mayor entusiasmo por la población, que se había adherido la víspera al Alzamiento Nacional":

Un repique general de campanas, los ecos de todas las bandas de música que repetían el tan entusiasta y popular himno de Riego, y los nutridos y continuados

\footnotetext{
30 Orellana, Francisco José: Historia del General..., pp. 912-913.

31 Soler Cantó, Juan: Historia de Cartagena, Cartagena, Librería Escarabajal, 1990, p. 217.

32 El Imparcial, 2 de octubre de 1868, p. 2.

33 Tornel, Cayetano; Grandal, Alfonso y Rivas, Ángel: Textos para la historia de Cartagena (s. XVI-XX), Cartagena, Ayuntamiento de Cartagena, 1985, pp. 147-148.

34 La Paz de Murcia, no 3567, 29 de septiembre de 1868, suplemento.
} 
vivas de un pueblo que en masa ocupaba lleno de júbilo todos los alrededores de la estación de ferrocarril hasta la casa consistorial, tales fueron las demostraciones con que se recibió y despidió al caudillo de la libertad..$^{35}$

Como en otros lugares, aquel que "tanto había luchado y padecido por romper las cadenas que oprimen á esta Nación esclava", ${ }^{36}$ saludó desde el balcón del Ayuntamiento de la ciudad. Posteriormente volvió a la ciudad cartagenera, de donde partió hacia Valencia el jueves 1 tras dar tres vivas a la Libertad, a la Soberanía Nacional y al pueblo de la ciudad ${ }^{37}$ en el muelle, justo antes de embarcar en presencia de los centenares de personas que habían acudido a despedirlo. La presencia de la flota rebelde de la que Prim era el miembro más resaltable resultó definitiva para que una plaza tan fuerte como Cartagena se uniese a la revolución en marcha. Fue él el más aclamado por la gente y el acicate principal para el triunfo de la Gloriosa en la ciudad.

El día 2 llegó a Valencia. La capital del Turia no traía buenos recuerdos para Prim, pues las guarniciones que habían estado allí en el pasado le habían fallado en sendas intentonas insurreccionales previas (la ocasión más grave tuvo lugar en 1865 , con él a pocos metros del puerto para liderarla y teniendo que huir apresuradamente) y que no obstante le brindó aquel día una gran acogida. El apoyo político a la revolución se plasmó en las decisiones que había tomado la Junta Revolucionaria valenciana a finales de septiembre, como la expulsión de los jesuitas, la abolición del impuesto de consumos y la supresión de la guardia rural. ${ }^{38}$ Volviendo a los actos políticos públicos, los dependientes del comercio se manifestaron con un busto de Prim por las principales calles de la ciudad, siendo recibidos con vítores y aplausos allí por donde pasaban, el día 30. El alcalde, Juan Piñol, invitó a los estudiantes y los miembros de los diferentes gremios a dar la bienvenida al general, acompañando a la comisión municipal y a la banda local de música. ${ }^{39}$ De nuevo, la sublevación fue previa a la llegada de Prim, quien fue recibido como el impulsor de la revolución que realmente era, pero, al igual que había sucedido en Málaga, su presencia no fue determinante en la adhesión valenciana al alzamiento.

Un "vaporcito" y varias falúas ocupados por los miembros de la Junta Revolucionaria y el Ayuntamiento salieron a recibir a la fragata Zaragoza. Ya en el puerto, ambas comitivas se trasladaron en un tren especial a la estación central, donde esperaban comisiones de todas las corporaciones y fuerzas vivas de la ciudad. Llovió todo el día, pero no fue obstáculo para las muestras de júbilo y alegría ante el "ídolo del pueblo" que al fin había llegado a la ciudad, ${ }^{40}$ que se llenó de aclamaciones. Un desfile cívico fue organizado por las autoridades locales, al que acudió un gran número de personas y representaciones que portaban banderas de la Universidad, el Instituto y otras entidades de instrucción pública, junto a las de los gremios de comercio, mostrando una unidad diversa en torno a Prim. Encabezaban el desfile varios

35 La Paz de Murcia, no 3569, 1 de octubre de 1868, pp. 3-4.

36 El Avisador, $\mathrm{n}^{\circ} 1,1$ de octubre de 1868, p. 3.

37 La Iberia, $\mathrm{n}^{\mathbf{0}} 3679,5$ de octubre de 1868, p. 1.

38 Martínez Roda, Federico: Valencia y las Valencias, su historia contemporánea (1800-1975), Valencia, Fundación San Pablo CEU, 1998, p. 319.

39 Gascón Pelegri, Vicente: La revolución del 68, en Valencia y su reino, Castellón de la Plana, Sociedad Castellonense de Cultura, 1978, pp. 64-65.

40 Miquel i Vergés, Josep Maria: El general Prim, en España y en México, Ciudad de México, Ed. Hermes, 1949, p. 386 . 
carruajes que a su vez portaban a las corporaciones (la Universidad, el Instituto de Bachillerato, la Academia de San Carlos, los gremios y el comercio) y sus banderas, el Regente de la Audiencia, el prior del Tribunal del Comercio y los cónsules, entre otros. Por último, la carroza del general mitificado, acompañado de una numerosa representación de las Milicias ciudadanas. ${ }^{41}$ Este fragmento de su discurso al pueblo desde el palacio de la Capitanía General en el que recordaba la necesidad de la unión entre los liberales tuvo una gran difusión a nivel nacional en aquellos meses:

La libertad estaba dormida en España, no estaba muerta, porque no puede morir. Tiranos insolentes la habían creído enterrada, y habían arrojado sobre ella una losa sepulcral. (...) La libertad está reconquistada y se consolidará de tal manera que podemos decir que lo estará para siempre. Todas las aspiraciones de los partidos liberales quedarán satisfechas. Olvidemos para siempre antiguas denominaciones políticas y consagrémonos todos de buena fe al triunfo y consolidación de la libertad. ${ }^{42}$

El gentío en torno al edificio de la Capitanía General era tan numeroso que las personas no sólo ocupaban la calle, sino también los balcones, los árboles, los carruajes aparcados, las verjas... Todos estaban deseosos de contemplar de nuevo al marqués de los Castillejos, quien, viendo la situación ante la que se encontraba optó por llegar al puerto atravesando el Parque de Artillería, una opción al parecer con menos gente, aunque la idea fue inútil: fue de nuevo rodeado y vitoreado en su regreso a la flota. Consiguió embarcar para Barcelona a las cuatro de la tarde. El impacto en la ciudad fue tal que la publicación quincenal de carácter local El Panorama, que se decía "ajeno a la política", le dedicó la portada y un extenso artículo laudatorio, además de un retrato a raíz de su paso por Valencia.

\section{Cataluña: éxtasis público en Barcelona y el retorno a casa en Reus}

Si en todas partes fue recibido con aclamaciones, cuando el sábado 3 de octubre Prim apareció en la Ciudad Condal el entusiasmo rozó el delirio. ${ }^{43}$ Cuatro días antes ya recorría las calles de la ciudad un carruaje adornado con banderas en el que se llevaba el retrato del general, alumbrado con hachas de cera. Dicho cuadro era vitoreado por los numerosos grupos que acompañaban al carruaje y por los viandantes que se cruzaban con él. ${ }^{44}$ Lo mismo ocurría con el busto de Espartero. Los cuadros de ambos fueron colocados en el frontispicio de la fachada del Ayuntamiento y también en el exterior de numerosas casas particulares, como recoge la prensa local. ${ }^{45}$ A pesar de las dudas de los días precedentes sobre el auténtico paradero de Prim, ${ }^{46}$ finalmente

\footnotetext{
41 Monlleó Peris, Rosa: La Gloriosa en Valencia (1864-1869), Valencia, Ed. Alfons el Magnànim, 1996 , p. 66.

42 Anguera, Pere: Prim. Biografía de..., pp. 530-531.

43 Poch Noguer, José: El General Prim..., p. 108.

44 Martínez Bárcena, Jorge: Nacionalismo español y simbología urbana: Madrid en su contexto nacional e internacional entre la Guerra de la Independencia y el final de Restauración, Madrid, Tesis Doctoral, Universidad Complutense de Madrid, 2003, p. 315.

45 El Telégrafo, $\mathrm{n}^{\circ}$ 1, 30 de septiembre de 1868, p. 2. Ver también Diario de Barcelona, $\mathrm{n}^{\circ}$ 273, 4 de octubre de 1868 , p. 4.

46 Diario de Barcelona, $\mathrm{n}^{\circ} 270$ y 271, 1 y 2 de octubre de 1868, p. 2 en ambos casos.
} 
llegó la noticia de su arribada. Los cañones del castillo de Montjuich y las campanas de toda la ciudad invitaron a los catalanes a recibir a su hijo ilustre durante toda la mañana, cuya llegaba anunciaban. Así lo describió la prensa:

Un cañonazo disparado á las diez de la mañana, otro á las doce y otro á las dos de la tarde, anunciaron la llegada de la escuadra española, á cuyo bordo iba el general. El estampido del último atrajo al muelle, muralla de mar y falda de Monjuich (sic), un inmenso gentío de que formaban parte infinidad de vecinos de los pueblos comarcanos, ansiosos de participar del espectáculo que presencio Barcelona. ${ }^{47}$

Fue recibido por los barceloneses "de un modo fastuoso, espléndido hasta la exageración" ${ }^{48}$ El barco de guerra León lo acercó al puerto de la ciudad. Una vez allí, lo que encontró fueron arcos del triunfo en las calles, flores, banderas y estandartes, numerosas jóvenes ataviadas para la ocasión con vestidos regionales de Cataluña y Aragón, coros y bandas que tocaban de forma ininterrumpida... Con todos esos elementos se dio forma al entusiasmo que rodeaba a Prim, quien montaba su caballo andaluz especialmente decorado para la ocasión. Le esperaban las autoridades de la Junta, el ayuntamiento, la universidad, los magistrados y otras instituciones locales. Junto a ellos, el pueblo y, sobre todo, su madre Teresa, a quien Prim estaba profundamente unido (su correspondencia da buena muestra de ello) y quien no se perdió esa jornada de gloria para su hijo a pesar de su avanzada edad. ${ }^{49}$ Madre e hijo se encontraron en un silencioso abrazo en el mismo puerto que simbolizó la emoción reinante en ese momento en la capital catalana.

No obstante, al comienzo de la jornada hubo un momento de tensión cuando Prim subió las escalerillas del embarcadero. En ese instante se difundió rápidamente un grito ("unánime", según algunas fuentes) ${ }^{50}$ para que el general quitara de su gorra la corona real que estaba cosida a ella (“¡Fuera la corona!” se oyó). El conde de Reus, quien rechazaba de plano la República como forma de gobierno, se negó a obedecer esos gritos. Como respuesta, gritó desde el carro que lo transportaba: "Catalans, catalans, voleu correr molt, potser massa. No vulgueu correr tant, que podem caure" ("Catalanes, catalanes, queréis correr mucho, quizá demasiado. No queráis correr tanto, que podemos caer"). ${ }^{51}$ Los ánimos se calmaron poco a poco. Por suerte para él, durante el trayecto hasta la plaza de San Jaime, entonces llamada "de la Constitución", los vítores y las protestas se entremezclaron, venciendo los primeros finalmente, rodeados por una lluvia de flores.

La presencia de público era tan numerosa, con cerca de 12.000 personas para escuchar sus palabras, (“difícilmente á las personas reales se ha dispensado una acogida tan entusiasta") ${ }^{52}$ que incluso se temió alguna desgracia o accidente. Las casas y calles del recorrido estaban engalanadas con banderas, colgaduras y otros elementos simbólicos. ${ }^{53} \mathrm{Su}$ entrada en la capital catalana supuso uno de los más multitudina-

47 El Telégrafo, $\mathrm{n}^{\circ} 5,4$ de octubre de 1868, p. 2.

48 El Faro Bisbalense, n 173, 11 de octubre de 1868, p. 2.

49 Prim i Serentill, Josep Maria: Joan Prim, revolucionari i home d'estat, Reus, Fundació Roger de Belfort, 1988, pp. 205-206.

50 El Telégrafo, $\mathrm{n}^{\mathrm{o}} 5,4$ de octubre de 1868, p. 3.

51 Poch Noguer, José: El General Prim..., p. 109.

52 El Telégrafo, $\mathrm{n}^{\circ} 5,4$ de octubre de 1868, p. 3.

53 Anguera, Pere: Prim. Biografía de..., p. 531. 
rios recibimientos populares de la trayectoria política de Prim, "una ovación como nunca haya visto Barcelona". ${ }^{4}$ Al fin, tras un silencio que no fue fácil lograr, desde el balcón del Ayuntamiento se dirigió al pueblo con palabras llenas "de fuego y de patriotismo" 55 y terminó lanzando vítores, como solía hacer, a la soberanía nacional, al Ejército y a la Marina. Eso sí, en un acto de prudencia decidió salir al balcón del edificio con la cabeza descubierta, evitando mostrar de nuevo la gorra que había provocado el incidente desagradable con los republicanos. Por la tarde acudió al Salón de la Lonja, donde fue celebrada una sesión de la Junta Revolucionaria en su honor, tras la que dio un discurso en el que vinculó libertad y orden, sus dos ideas-fuerza. En esa ocasión aprovechó para reclamar la unidad de todos los liberales ante la nueva época que se iniciaba. ${ }^{56}$ Sus palabras fueron recibidas con escepticismo desde algunos sectores, tanto republicanos como monárquicos, que mantenían serias diferencias en cuanto a la evolución política que debía tomar el país tras la Revolución.

A pesar del éxito rotundo de su llegada a Barcelona, Prim decidió viajar ese mismo día hacia Tarragona, que también estaba en manos de los revolucionarios. Viajó de noche y a las nueve de la mañana del 4 autoridades y vecinos ya le estaban procurando una calurosa acogida. Heras Caballero recoge la descripción que hizo Magriñà de los acontecimientos. Se trata de un testigo de primera mano, pues fue uno de los comisionados que acudieron a dar la bienvenida personalmente a Prim a bordo de la Zaragoza: "no es posible describir el entusiasmo delirante que se apoderó de la multitud, pues los vivas ensordecían por completo la música". ${ }^{57}$ Cabe imaginarse el ambiente festivo que rodeaba a la comitiva del que se consideraba líder de la rebelión contra Isabel II. La plaza de María Cristina de la ciudad pasó a ser la plaza de Prim, mientras que la plaza de la Aduana tomó el nombre de José Malcampo, acompañante del reusense. Además, fue nombrado hijo predilecto de la ciudad. Poco después tomó un tren hacia Reus.

A primera hora de la tarde del día 4 llegó a su ciudad natal, donde de nuevo fue aclamado por la multitud con el repique de fondo de las campanas de la ciudad y con los edificios decorados con colgaduras. ${ }^{58}$ En su discurso en la sede de la Junta Revolucionaria reclamó la unidad "de todos los buenos" como mejor garantía de la libertad y exigió la defensa del orden para asegurar su permanencia. ${ }^{59}$ La sincera admiración de sus paisanos quedó plasmada en los acontecimientos y actos de aquel día.

\section{Madrid: última parada}

Junto a la travesía marítima de Prim y su paso por Reus, la importancia simbólica de Madrid, final y culmen de este viaje, hace necesario que aparezcan los acontecimientos sucedidos en la capital. Allí, desde el triunfo en Alcolea habían comenzado las decisiones en favor del levantamiento, comenzando por los cambios en la nomencla-

\footnotetext{
54 El Faro Bisbalense, n 173,11 de octubre de 1868, p. 2.

55 Anguera, Pere: Prim. Biografia de..., p. 132.

56 Poch Noguer, José: El General Prim..., pp. 110-111.

57 Heras Caballero, Pedro Antonio: La revolució de setembre de 1868 a Tarragona, Tarragona, Ayuntamiento de Tarragona, 1981, p. 79.

58 Anguera, Pere: Prim. Biografia de..., p. 533

59 Boletín Oficial de la Junta Revolucionaria de Reus, nº 6, 7 de octubre de 1868, p. 1.
} 
tura de las calles: el nombre de la antigua plaza de Santa Fe fue sustituido por el de Plaza de Topete. La plaza de Isabel II recibió el nombre de plaza de Prim, mientras que la de Oriente se convirtió en la de la Marina, y la de Herradores, de Serrano. La calle de la Reina recibió el nombre de Prim, denominación que mantuvo hasta la Restauración. ${ }^{60}$ La situación se descontroló hasta llegar a la existencia de más de una calle con el apellido del reusense, con la confusión que esa situación generaba. Algún periodista llegó a solicitar al ayuntamiento capitalino que las numerase sin cambiar al nombre, naciendo así "la calle $2^{\mathrm{a}}$ de Prim", entre otras. ${ }^{61}$ Se observaron variaciones parecidas en otras ciudades españolas; entre otras en Valladolid, Guadalajara o Bilbao. ${ }^{62}$

Para llegar a la capital el general tomó un tren a Vimbodí, aún en la provincia de Tarragona, para luego desplazarse por carretera hasta Lérida y de ahí de nuevo en ferrocarril hacia Madrid. En este último trayecto tuvo que detenerse en todas las estaciones para recibir el agasajo de los habitantes de los pueblos y ciudades que atravesaba. Finalmente, a las 3 de la tarde del 7 de octubre llegó a la estación de Vallecas, entonces municipio separado de Madrid, y allí se tributó un recibimiento multitudinario al tren "revestido de coronas, gallardetes, banderas y pabellones". Se repitieron escenas ya conocidas y el frenesí popular obligó a Prim a desplazarse a caballo hasta la puerta de Atocha. Una vez allí, se organizó el cortejo oficial, que atravesó las calles adornadas, igual que en el resto de localidades, con colgaduras y cuadros que representaban a los protagonistas de la Revolución. ${ }^{63}$ Galdós relató así los acontecimientos de los días 7 y 8 de octubre, repletos de entusiasmo popular:

Vi la entrada del general Prim, el héroe popular de aquella revolución. El delirio de la multitud llegó al frenesí. (...) Desde el balcón del Ministerio hablaron Prim y creo que Topete. El embravecido oleaje de la multitud creció de tal modo, que no pudimos entender lo que dijeron los caudillos de la Revolución. ${ }^{64}$

Los relatos de lo sucedido en aquellos días que publicaron los diarios aportan descripciones bastante similares. Se destacaba (y quizá se exageraba en parte) la cantidad de personas congregadas para ver con sus propios ojos al héroe Prim y regalarle un recibimiento festivo, en el que plasmaban su admiración hacia él, pero también al nuevo episodio de su trayectoria política que acababa de comenzar:

La brillantísima acogida [sic] que en la tarde de ayer ha dispensado el heroico Pueblo de Madrid al ilustre general Prim, es superior á toda ponderación. Jamás, jamás ningún poderoso de la tierra ha recibido una ovación más espontánea, más significativa, ni más brillante. ${ }^{65}$

60 De Répide, Pedro: Las calles de Madrid, Madrid, Ediciones La Librería, 1995, p. 567.

61 La Época, $\mathrm{n}^{\circ}$ 6430, 5 de diciembre de 1868, p. 4.

62 Para el caso madrileño, El Imparcial, 1 de octubre de 1868, p. 2; para los demás, De la Fuente Monge, Gregorio: Los revolucionarios de..., p. 102.

63 Anguera, Pere: Prim. Biografía de..., p. 534.

64 Vidal Santos, Miguel: Salvapatrias y cruzados. Historias de los golpes de Estado en España, Madrid, EspasaCalpe, 2002, p. 98.

65 La Iberia, $\mathrm{n}^{\mathrm{O}} 3682,8$ de octubre de 1868, p. 1. 
Este ejemplo de La Iberia no fue el único. La Correspondencia de España habla de "multitudes que rodeaban la casa" en la que se alojaba Prim, haciendo guardia permanente. El monárquico La Esperanza detalla el recibimiento y enumera a todos los componentes de la comitiva y añade que cuando Prim llegó al Congreso, "entró empujado por la multitud, y quiso hablar, pero no pudo. (...) Tal era la afluencia de gente y tantos y tan atronadores los aplausos y vivas, que fue imposible hacer entender al público que el general deseaba hablar." Las aglomeraciones de público alcanzaron tal envergadura ("un gentío inmenso, que en momentos dados se condensaba hasta causar espanto" $)^{66}$ que se decidió cambiar el itinerario diseñado para evitar posibles problemas de seguridad. Ya más de una semana antes de que Prim llegase comenzaron los preparativos oficiales para recibirlo. El Ministerio de Gobernación colgó un retrato suyo de uno de sus balcones el día 29 de septiembre. ${ }^{67}$ Frente al Ministerio de Hacienda en la calle de Alcalá, pocos días más tarde se colocó un arco de musgo adornado con banderolas y gallardetes "por donde pasará el general Prim", ${ }^{68}$ La colocación de estas arquitecturas efímeras se llevó a cabo por voluntarios del propio ministerio, quienes además se pusieron a disposición del vecindario de la zona, ante la más que probable ornamentación de las calles aledañas al recorrido previsto para la comitiva del general.

La "abigarrada muchedumbre" madrileña estaba "electrizada". ${ }^{69}$ No se escatimaba en los adjetivos usados para describir el ambiente de la ciudad en aquellos días. Vítores, arcos del triunfo y calles engalanadas eran elementos habituales en estas ocasiones. Por si fuera poco, con motivo de la llegada de Prim se abrió una suscripción voluntaria por parte de los comerciantes de Madrid para cubrir parte de los gastos. ${ }^{70}$ En ella fueron lanzadas coronas, ramos de flores y poemas, en un ambiente festivo y con la presencia de músicos que interpretaban marchas militares. A todo ello Prim respondía con vivas a la libertad, la soberanía nacional, a Serrano y a Topete. Diversas fuerzas del pueblo y de la marina y gran número de sargentos emigrados que habían retornado tras el triunfo de los revolucionarios desfilaban en la cabecera del desfile, en un claro gesto simbólico. Un carruaje, representando un barco, precedía también al general, y desde él se soltaban palomas y se lanzaban flores al público. ${ }^{71}$ Un íntimo colaborador de Prim, Ricardo Muñiz, fue testigo y narró los acontecimientos: “entró por la Puerta de Alcalá, Prado y calle de Alcalá al Ministerio de la Gobernación, donde residíamos la Junta revolucionaria”, á quienes abrazó con efusión y ternura, abriendo él mismo el balcón principal, desde donde arengó al pueblo, pronunciando por primera vez sus tres famosos "jamases" 72 dedicados a los Borbones.

El abrazo público que se vio en el balcón de la céntrica Puerta del Sol con Serrano tuvo un alto simbolismo, como metáfora de las distintas tendencias políticas que habían colaborado en el triunfo de la revolución. Hubo un gran contraste entre

66 La Correspondencia de España, $\mathrm{n}^{\mathrm{o}} 3977,8$ de octubre de 1868, p. 2. La Esperanza, $\mathrm{n}^{\mathrm{o}} 7358,8$ de octubre de 1868, pp. 1-2. El Imparcial, 8 de octubre de 1868, p. 3.

67 La Correspondencia de España, $\mathrm{n}^{\circ} 3969,30$ de septiembre de 1868, p. 1.

68 El Imparcial, 7 de octubre de 1868, p. 3.

69 Santovenia, Emeterio: Prim, el caudillo..., p. 190.

70 La Iberia, $\mathrm{n}^{\circ} 3680,6$ de octubre de 1868, p. 2.

71 El Imparcial, 8 de octubre de 1868, p. 3.

72 Muñiz, Ricardo: Apuntes históricos sobre la revolución de 1868, Madrid, Imp. de Fortanet, volumen 1, 18841885 , pp. $248-249$. 
el recibimiento descrito para Prim con aquel que se hizo a Serrano cuatro días, antes entre un gentío bastante menos numeroso en las calles, a pesar de que el duque de la Torre había vencido en la decisiva batalla del puente de Alcolea el día 28. El mencionado abrazo en Sol bien pudo ser en el fondo una estrategia del duque de la Torre para unir su imagen a la del general militar. Serrano triunfa en Alcolea; pero es Prim quien recoge los vítores y el calor de las muchedumbres de Barcelona y de Madrid. ${ }^{73}$ La "usurpación" por parte de Prim de los logros de Serrano llegó hasta el punto de que desde el pueblo se compuso y se popularizó una copla que cedía al de Reus el triunfo en tierras cordobesas:

En el puente de Alcolea,
la batalla ganó Prim,
por eso le cantamos
en las calles de Madrid. ${ }^{74}$

Aunque Prim no había tenido ningún papel en el campo de batalla de Alcolea, los hechos se transformaron para adaptarlos y contribuir a la gloria y leyenda del general. De ahí que Serrano buscase el abrazo público con él en la Puerta del Sol cuando éste llega a la capital. Cuanto más vinculados se los viera, mejor sería para la imagen pública de Serrano. La rivalidad entre ambos era indudable y había habido muestras durante la propia Revolución: Serrano llegó a sospechar que la comitiva que acudió en su busca a Córdoba en realidad pretendía entretenerlo y retrasar su llegada a Madrid con el fin de que Prim arribase antes a la capital y acaparase un recibimiento que hiciese sombra al suyo ${ }^{75}$ llevándose así toda la gloria y el mérito, por lo que recibió a los enviados de forma bastante destemplada. De todas formas, parece que la envidia era unidireccional, pues el conde de Reus pidió a su ayudante Muñiz que en Madrid se recibiera "con grande ostentación y entusiasmo al duque de la Torre y sus heroicos soldados" (reconocido por el propio ayudante) ${ }^{76}$, como así se hizo, pues en ambos casos hubo "una frenética alegría, y un entusiasmo popular y una ovación, indescriptibles". ${ }^{77}$

Por otra parte, las comparaciones entre Prim y Espartero habían sido continuas y el recibimiento capitalino al reusense en octubre de 1868 fue una nueva oportunidad para contrastar a ambos. De ello participaron tanto autores tanto contemporáneos a los hechos como otros posteriores. ${ }^{78}$ En la historiografía se ha consolidado un consenso que defiende que ni siquiera Espartero a finales de septiembre de 1840, cuando entró en la capital como Regente provisional con Isabel II y su hermana tras la renuncia de María Cristina, había conseguido un recibimiento de la envergadura del que tuvo Prim en 1868.

\footnotetext{
73 Riera, Augusto: Don Juan Prim y Prats, Barcelona, Ramón Costa, 1923, p. 2.

74 De La Fuente Monge, Gregorio: Los revolucionarios de..., p. 65.

75 Santovenia, Emeterio: Prim, el caudillo..., pp. 187-188.

76 Muñiz, Ricardo: Apuntes históricos sobre..., p. 245.

77 González Tablas, Ramón, y Toral y Velázquez, José: Diario de las operaciones militares de la Revolución Española con documentos interesantes sobre la batalla de Alcolea. Comprende desde el 18 de setiembre al 8 de octubre de 1868, Madrid, Imprenta de Miguel Guijarro, 1869, p. 46.

78 Miquel i Vergés, Josep Maria: El general Prim..., pp. 387-388. También en Poch Noguer, José: El General Prim..., p. 112, y Muñiz, Ricardo: Apuntes históricos sobre..., p. 248.
} 
La Gloriosa Revolución y sus consecuencias supusieron la máxima popularidad para Prim que mostró la capacidad de movilización de su persona. "Su nombre decidió a los militares, alentó a los tímidos, agradó a las masas populares" escribió su biógrafo Riera. ${ }^{79} \mathrm{El}$ militar catalán era "el primitivo iniciador de la Revolución, su representante, su ídolo, el héroe de la libertad, el árbitro de España” que todo lo controlaba ${ }^{80}$ Estas palabras, aparecidas en una honra fúnebre a su muerte, ya estaban presentes en los meses posteriores a la Gloriosa. El extremo de esta situación se dio cuando aparecieron en Madrid papeletas litografiadas en las que se le proponía para Emperador de España, con las siguientes palabras: "Por plebiscito debemos constituir inmediatamente gobierno sin necesidad de recurrir a un golpe de estado tan inevitable como doloroso, votando para cubrir la vacante al trono al Excmo. Sr. D. Juan Prim y Prats, con el título de Juan I, Emperador". ${ }^{81}$ Aquel "ofrecimiento" de la Corona era la culminación del carisma portado por Prim en aquellas jornadas, y también posteriormente.

\section{Conclusiones}

De forma habitual se ha difundido una imagen del general Prim que lo presentaba como una figura revulsiva que fue llevando la mecha de la revolución en su recorrido por las ciudades más importantes de la costa mediterránea española, al tiempo que Serrano se encargaba de las operaciones en tierra de una forma casi marginal a ojos de la opinión pública. Sin embargo, a la luz de la investigación realizada para este artículo, se muestra que, aunque no puede decirse que esa percepción sea falsa, no es del todo exacta. Sí es cierto que los actos de Serrano quedaron más desdibujados para la población en general en comparación con Prim, una cabeza "más visible" del movimiento, pero, como se ha visto, el catalán participó en una maniobra que, vista en su conjunto, sirvió más para consolidar la revolución que para expandirla.

Cuando se contempla la sucesión de agasajos y homenajes que recibió en cada etapa de dicho viaje, es fácil constatar la importancia que tenía su figura. Sin embargo, su presencia personal directa sólo fue el desencadenante de los acontecimientos en cuatro casos concretos. Dos de ellos estratégicamente menores dada su situación e importancia general (Tarifa y Algeciras) y dos más, esos sí, fundamentales: Ceuta, por motivos geográficos obvios, y Cartagena, por su importancia logística para el Ejército y la Marina, pero también por el impulso psicológico que sería para el ánimo de los revolucionarios contar con una plaza tan fuerte. A éstos se podrían añadir dos éxitos "indirectos" más, las ciudades de Murcia y Granada, aunque con el apunte de que en esas ocasiones la influencia de Prim fue "a distancia". Su carisma era tal, que en el primer caso a los revolucionarios murcianos les bastó con utilizar su presencia en Cartagena para inducir a la ciudad al alzamiento, mientras que en el segundo una misiva enviada por el propio Prim desde Málaga constituyó el desencadenante de la adhesión de la ciudad. Sin embargo, en el resto de paradas de su travesía marítima, el

79 Riera, Augusto: Don Juan Prim..., p. 28.

80 De La Unión, Patricio: El héroe y la víctima de la libertad, y el juicio de la revolución: verdades, misterios y desengaños, Madrid, Imp. de Antonio Pérez Dubrull, 1871, p. 17.

81 Carro Martínez, Antonio: La Constitución de 1869, Tesis Doctoral, Madrid, Universidad Complutense, 1950, p. 70 . 
paso hacia la adhesión al alzamiento ya se había dado cuando la flota en que viajaba Prim se asomó a la bocana del puerto (Málaga, Valencia, Barcelona y Tarragona) o éste se bajó del tren (Jerez de la Frontera, Reus y Madrid).

Otro elemento nuevo que aporta este artículo se produce con el caso de Almería. La bibliografía centrada en la Gloriosa de un modo global menciona de pasada a dicha ciudad como una de las paradas de la travesía en las que la aparición del general fue clave para que se uniera a la Revolución, sin profundizar más en la cuestión. Esta es la primera investigación que estudia esta fase litoral de la Gloriosa en su conjunto (y no solamente a una escala centrada en un único municipio) y se corrige ese error heredado en diversas obras durante casi siglo y medio, contextualizando el verdadero momento en que los almerienses se adhirieron a la sublevación y la no presencia de Prim en dicha ciudad.

Más allá del papel del militar catalán en cada caso, en todas las ciudades se produjeron actos de agasajo hacia él. Sin excepción (no hay que olvidar el viaje en tren desde Reus a Madrid, donde hubo de detenerse casi en cada apeadero) se buscaba compartir el fervor revolucionario triunfante con uno de los hombres que habían hecho posible el éxito de la "Gloriosa", quien en realidad la personificaba. Su llegada era como una culminación que sellaba el compromiso con los ideales revolucionarios por parte de la ciudad de la que se tratase. Existió un patrón de comportamiento que se repetía en cada parada, independientemente de la fecha de formación de las Juntas Revolucionarias, consistente en bandas de música, recepciones en el puerto por parte de una nutrida representación de delegaciones municipales y corporativas, cenas, discursos en los balcones de los edificios más relevantes de cada ciudad, etcétera.

La legitimidad carismática que se le confería explica estos comportamientos en los que él era protagonista y destinatario al mismo tiempo; las capacidades que se le atribuían eran la base del reconocimiento y la suposición de su valía para las tareas políticas que iba a comenzar a desempeñar. La adhesión municipal a la revolución fue en general algo independiente de la persona de Prim: muchos lugares de España se unieron a la misma sin que el reusense pasase por ellas. Pero al mismo tiempo, de lo que no cabe duda es de la importancia concedida a la figura de Prim tanto en zonas donde aún no se había formado una Junta Revolucionaria como en aquellas ciudades que sí se habían unido ya al movimiento. Los deseos de presenciar en persona al héroe de África que ahora se había convertido en líder del movimiento revolucionario eran intensos y estaban muy difundidos. Era siempre la referencia más importante en los concurridos actos de celebración. La prensa local y nacional siguió el transcurso de la travesía de la escuadra revolucionaria, dando buena cuenta de los acontecimientos que iban sucediéndose. Se ha visto cómo en las crónicas eran frecuentes las menciones a que el número de personas era tan elevado en las calles, que se temía alguna avalancha o algún problema de orden público incluso.

Un hombre por sí solo no puede extender la revolución a todo un país, pero, en virtud de las características que se le atribuyan en cada momento y de la concatenación de otras circunstancias, sí puede impulsar y reforzar indirectamente la difusión de la rebelión en marcha, sobre la base de su liderazgo carismático. Al mismo tiempo, los actos de homenaje con los que se le honraba daban un efecto multiplicador y servían como elementos propagandísticos de exhibición de la fuerza del movimiento revolucionario. ¿Fue importante? Por supuesto: Prim ocupó en todo momento el puesto de dirigente castrense de mayor calado, pero no siempre fue decisivo para que las distintas ciudades se unieran a su causa. Tuvo un papel primordial en el 
nacimiento de la Gloriosa, pero su viaje por el Mediterráneo fue en sí mismo más importante para el reforzamiento de la Revolución en el conjunto de España que para su expansión directa.

\section{Referencias bibliográficas}

\subsection{Estudios}

Anguera, Pere. Prim. Biografia de un conspirador, Barcelona, Edhasa, 2003.

Bahamonde, Ángel y Martínez, Jesús A.: Historia de España. Siglo XIX, Madrid, Cátedra, 2011.

Bernal, Antonio Miguel: “Andalucía caciquil y revolucionaria (1868-1936)", en VV.AA: Historia de Andalucía. Volumen VIII: La Andalucía contemporánea, Barcelona, Cilsa, 1981, pp. 13-63.

Biografia del General Don Juan Prim, Conde de Reus y Marqués de Castillejos, Madrid, Despacho Calle Juanelo 19, 1876.

Bretón García, Alicia: La Gloriosa en Málaga. Estudio Económico y Político sobre la Revolución de 1868 en Málaga, Málaga, Diputación Provincial de Málaga, 1986.

Caro Cancela, Diego: Andalucía y la Revolución del 68, Granada, Caja Granada, 2008.

Carro Martínez, Antonio: La Constitución de 1869, Tesis Doctoral, Madrid, Universidad Complutense, 1950.

Comellas, José Luis: La España de la generación romántica, Barcelona, Folio, 2009.

De la Fuente Monge, Gregorio: Los revolucionarios de 1868. Élites y poder en la España liberal, Madrid, Marcial Pons, 2000.

De la Unión, Patricio: El héroe y la víctima de la libertad, y el juicio de la revolución: verdades, misterios y desengaños, Madrid, Imp. de Antonio Pérez Dubrull, 1871.

De Lara, D. M. M.: Cronista de la Revolución Española de 1868, Barcelona, Imp. de Celestino Verdaguer, 1868.

De Répide, Pedro: Las calles de Madrid, Madrid, Ediciones La Librería, 1995.

Díaz de Escovar, Narciso: Anales de Málaga: algunos datos sobre la revolución de septiembre (18 de septiembre de 1868 a 22 de enero de 1869), Málaga: s.n., ca. 1869.

Esdaile, Charles J.: "Prohombres, aventureros y oportunistas: la influencia del trayecto personal en los orígenes del liberalismo en España” en Alda Blanco y Guy Thompson (eds.): Visiones del liberalismo: politica, identidad y cultura en la España del siglo XIX, Valencia, Universidad de Valencia, 2008, pp. 65-86.

Gascón Pelegri, Vicente: La revolución del 68, en Valencia y su reino, Castellón de la Plana, Sociedad Castellonense de Cultura, 1978.

Gómez Barceló, José Luis: "El siglo XIX", en VVAA. Historia de Ceuta. De los orígenes al año 2000. Volumen 2: De los Austrias al siglo XXI, Ceuta, Instituto de Estudios Ceutíes, 2009, pp. 118-209.

González Tablas Ramón; Toral y Velázquez, José: Diario de las operaciones militares de la Revolución Española con documentos interesantes sobre la batalla de Alcolea. Comprende desde el 18 de setiembre al 8 de octubre de 1868, Madrid, Imprenta de Miguel Guijarro, 1869. 
Heras Caballero, Pedro Antonio: La revolució de setembre de 1868 a Tarragona, Tarragona, Ayuntamiento de Tarragona, 1981.

Martínez Bárcena, Jorge: Nacionalismo español y simbología urbana: Madrid en su contexto nacional e internacional entre la Guerra de la Independencia y el final de Restauración, Madrid, Tesis Doctoral, Universidad Complutense de Madrid, 2003.

Martínez López, Fernando: Los republicanos en la política almeriense del siglo XIX, Málaga, Unicaja, 2006.

Martínez López, Fernando: "Del sufragio universal a la solidaridad. Salmerón en la política republicana almeriense (1869-1908)”, en María Cruz Amate Martínez. (coord.) Nicolás Salmerón y Alonso (1837-1908). Semblanzas, Almería, Instituto de Estudios Almerienses, 2008, pp. 133-198.

Martínez Roda, Federico: Valencia y las Valencias: su historia contemporánea (1800-1975), Valencia, Fundación Universitaria San Pablo CEU, 1998.

Miquel i Vergés, Josep Maria: El general Prim, en España y en México, Ciudad de México, Ed. Hermes, 1949.

Monlleó Peris, Rosa: La Gloriosa en Valencia (1864-1869), Valencia, Ed. Alfons el Magnànim, 1996.

Morales Muñoz, Manuel: "La Gloriosa en Málaga: del clamor revolucionario al fracaso de las expectativas populares", Baetica, 16, 1994, pp. 395-413.

Muñiz, Ricardo: Apuntes históricos sobre la revolución de 1868, Madrid, Imp. de Fortanet, volumen 1, 1884-1885.

Orellana, Francisco José: Historia del General Prim, Barcelona, Empresa Editorial La Ilustración, Tomo II, 1872.

Pitkin, Hanna Fenichel: El concepto de representación, Madrid, Centro de Estudios Políticos y Constitucionales, 1985.

Poch Noguer, José: El General Prim, Madrid, Sarpe, 1986.

Prim i Serentill, Josep Maria: Joan Prim, revolucionari i home d'estat, Reus, Fundació Roger de Belfort, 1988.

Riera, Augusto: Don Juan Prim y Prats, Barcelona, Ramón Costa, 1923.

Santovenia, Emeterio; Prim, el caudillo estadista, Madrid, Espasa-Calpe, 1933.

Sanz Cruz, Mario: Faro de Mesa Roldán. (Apuntes para una historia), Almería, Instituto de Estudios Almerienses, 2003.

Soler Cantó, Juan: Historia de Cartagena, Cartagena, Librería Escarabajal, 1990.

Tornel, Cayetano; Grandal, Alfonso; Rivas, Ángel: Textos para la historia de Cartagena (s. XVI-XX), Cartagena, Ayuntamiento de Cartagena, 1985.

Vidal Delgado, Rafael: Gloria y muerte en Málaga. Tomo I. Una revolución en busca de un Rey, Málaga, Caligrama Ediciones, 2007.

Vidal Santos, Miguel: Salvapatrias y cruzados. Historias de los golpes de Estado en España, Madrid, Espasa-Calpe, 2002.

Weber, Max: Economía y Sociedad, Ciudad de México, Fondo de Cultura Económica, 1977.

Zurita Aldeguer, Rafael: "El Progresismo. Héroes e historia de la nación liberal" en María Cruz Romeo y María Sierra (coords.): La España Liberal. 1833-1874, Zaragoza, Marcial Pons-Prensas Universitarias de Zaragoza, 2014, pp. 317-346. 


\subsection{Prensa}

El Avisador [Murcia], 1 de octubre de 1868, n 1.

El Avisador Malagueño, suplemento, 22 de septiembre de 1868.

El Avisador Malagueño, 26 de septiembre de 1868.

Boletín Oficial de la Junta Revolucionaria de Reus, 7 de octubre de 1868, n 6.

La Correspondencia de España, 29 de septiembre de 1868, n 3968.

La Correspondencia de España, 30 de septiembre de 1868, no 3969.

La Correspondencia de España, 8 de octubre de 1868, nº 3977.

Crónica Mataronesa, 4 de octubre de 1868, $\mathrm{n}^{\circ} 40$.

Diario de Barcelona, 1 de octubre de 1868, $\mathrm{n}^{\circ} 270$.

Diario de Barcelona, 2 de octubre de 1868, $\mathrm{n}^{\circ} 271$.

Diario de Barcelona, 4 de octubre de 1868, $\mathrm{n}^{\circ} 273$.

La Época, 5 de diciembre de 1868, n 6430.

La Esperanza, 8 de octubre de 1868, n 7358.

El Faro Bisbalense, 11 de octubre de 1868, n 173.

El Guadalete, 22 de septiembre de 1868, nº 4892.

La Iberia, 5 de octubre de 1868, no 3679.

La Iberia, 6 de octubre de 1868, $\mathrm{n}^{\circ} 3680$.

La Iberia, 8 de octubre de 1868, no 3682.

El Imparcial, 1 de octubre de 1868.

El Imparcial, 2 de octubre de 1868.

El Imparcial, 7 de octubre de 1868.

El Imparcial, 8 de octubre de 1868.

El Panorama, $\mathrm{n}^{\circ} 43,15$ de octubre de 1868.

La Paz de Murcia, 29 de septiembre de 1868, no 3567.

La Paz de Murcia, 1 de octubre de 1868, $n^{\circ} 3569$.

El Telégrafo, 30 de septiembre de 1868, $\mathrm{n}^{\circ} 1$.

El Telégrafo, 4 de octubre de 1868, $\mathrm{n}^{\circ} 5$. 